\title{
Poverty Measurement and Policy
}

\author{
Bob Stephens
}

\section{Introduction}

The measurement of poverty is a contested academic exercise and also a very controversial political issue. There is no single, accepted method of either conceptualising or measuring poverty. Each method of analysis results in identifying a different proportion of the population (as having an inadequate standard of living). This means that for different family, age or ethnic groupings, there may be a greater (or lesser) likelihood of being poor. Inevitably, the determination of who is poor has a major impact on the choice of policy measures to al leviate and ameliorate that poverty.

Publication of the results of poverty analysis tends to be a highly visible exercise, politically loaded and with varying emotive, popular and sectoral responses. The government of the day is invariably held responsible for any adverse trends, despite having had only partial control over the causal mechanisms. And the political response may be at variance with the policy prescriptions arising from the evidence-based statistics. As all students and practitioners of public policy know, the first step is for the analyst to get an issue onto the political agenda, but after that the issue can take on a life of its own.

The aim in this article is to discuss the benefits and difficulties in measuring poverty. This requires discussion on the objectives of poverty measurement, and some of the technical issues that bedevil practitioners. In the process, we shall see the different ways in which poverty has been conceptualised and measured in $\mathrm{N}$ ew Zealand. The paper is set in the context of the Poverty M easurement Project (introduced in the aftermath of the 1991 benefit cuts). It explores the subsequent use made of those results in policy development post-2000, as well as the establishment by the M inistry of Social D evelopment of a set of living standard measures and deprivation scales. The final section considers how the different poverty measures can be utilised in the policy process, and examines their relative strengths and weaknesses for different political purposes. This analysis leads to the conclusion that a raft of measures is required if a full picture of those with low standards of living is to be obtained, and appropriate policy responses devised.

\section{The objectives of poverty measurement}

In most western societies there is a degree of concern for people who are poor. This concern may result from consideration of human rights, from a belief in social justice, or from purely selfish reasons. International covenants on human and social rights affirm that each individual and family hastheright to an adequatestandard of living, access to health care, housing of suitable quality and to educational opportunity. Covenants on rights provide for a minimum standard, sometimes with possibilities of access to legal recourse if the minimum standards are not met, but rights legislation is unable to prescribe the form and substance of policy itself.

Although there is no universal definition of social justice, many approaches stem from a social entitlements perspective. This implies that all members of society should havea minimum standard of living, with equality of access not only to all social services, but also to the law and to any possible redress to offset inherited disadvantages. It assumes that it will remain a social objective to eliminate poverty or hardship for those with an inadequate standard of living. Permitting each person to achievetheir potential requires at a minimum the abolition of poverty.

Even if it is argued that individuals mould their own fate, so that being poor is seen as a consequence of rational individual decision-making, there can still be a concern for the consequences of poverty. There may be 
a dislike of seeing people in rags and sleeping rough, a fear of crime associated with the poor obtaining sustenance illegally, or a worry that children growing up in poor families may not havean equal start in life. 0 thers may fear that current and future economic growth will becurtailed by the tax burden created by increased health and other costs resulting from poverty (or from direct attempts to reduce the prevalence of poverty)

Given this individual and societal concern for the removal of poverty, it is necessary to ascertain who are the poorest people, and what is the best method to assist them. Two broad solutions are feasible: the development of a short-term programme to reduce the incidence of poverty or the endorsement of long-term solutions to the causes of poverty. In either case, it is necessary to know what constitutes poverty, to have some mechanism for distinguishing the poor from the non-poor, and to create a theoretical or empirical structure for ascertaining the causes of poverty. In all of this, measurement is the inexorable first step.

We can suggest several uses for a poverty measure, all of which are inter-related:

- To provide a mechanism to target resources to those groups that have the greatest need. The development of an appropriate indicator requires an assessment of the relativeincidence (and severity) of poverty among different family types or socioeconomic groupings. It also relies on insights about the structure of poverty - the proportion of the total poor who are in each socio-economic group.

- To monitor theimpact over time of changing economic, social and demographic effects as well as policy decisions on the incidence and severity of poverty. To satisfy this objective requires regular, preferably annually, updating of the poverty measure.

- To calculatethedynamics of poverty- thelength of time that families or groups remain poor, whether there is movement in and out of poverty, and whether poverty is transmitted from one generation to the next. Longitudinal studies are required to achieve this objective.

- To act asa benchmark, reflecting a standard of adequacy for social security benefit payments, including any additional assistance to offset the extra cost of children. A measure of adequacy of living standards independent from the benefit system itself is required.
The benchmark can also be used to calibratethelevel at which income tests become operative.

- For short-term poverty alleviation, to determinethecost to the taxpayer of eliminating poverty. This calls for a calculation of income shortfall, or poverty gap, and also for an assessment whether income maintenance is more cost-effective in cash or in-kind.

- To investigate the causes of poverty. This will inform decisions about the appropriate mix of short-term measures and longer-term solutions to address the causes of poverty. The requirement here is a data set that enables both proximate causes (e.g. sole parenting) and ultimatecauses (e.g. low self-esteem, leading to sole parenting) to be determined.

In short, a measure of poverty has to satisfy a variety of different objectives. It is likely that each will require a different approach. M easurement in itself obviously does not mean that poverty or hardship will be eliminated: thereality facing any government is thelimit on its ability to redistribute resources.

\section{Establishing a poverty measure}

Theneed for consistency between the conceptualisation of poverty and the techniques used to measure poverty is well recognised. However, in most instances the determining factor has been the availability of (and cost of obtaining) data. Counting the poor is thusan exercise in the art of the possible rather than value-free evidence than can be immediately reformulated into policy prescriptions. Three distinct steps can be identified:

\section{Refining the concept of poverty}

M ost poverty measures are based on an external, or objective, assessment of family circumstances, rather than the family's own (subjective) view. O bjective assessments rely upon the judgement of experts, but most of them have never been poor, they often impose arbitrary standards, or allow themselves to be guided by secondary data collected for other purposes. Subjective evaluations stem from the feelings of individuals as to the adequacy of their standard of living. They may reflect essential underlying valuessuch as democracy and citizenship. O ne way of reducing the gap between objective and subjective evidence is to use focus groups to draw upon the experiences of those living on low wages or social security benefits. Focus groups allow participants time to work 
through theissuesand comeup with an agreed minimum basket of goods and services. (Results from the Poverty $M$ easurement Project do in fact show a high degree of consistency across such focus groups. The results are intuitively plausible, placing the poverty lineat a level very similar to the N ew Zealand Superannuation pension.)

\section{Developing a Poverty Indicator}

Three broad approaches to the development of an indicator have been devised:

1) Consumption of specific goods and services. The concern here is with 'outcomes' loosely defined reflected for example in the fact that people have insufficient to eat, have poor clothing, are unableto afford health care or have sub-standard shelter. The approach requires a specific questionnaire, and must take care to separate deliberate choice from constraint in the consumption of specific items. It should cover the use of assets as well as consumption flows, thus providing a realistic picture of achieved standards of living.

2) Total expenditure. An indicator is developed using thetotal spent in order to achievea minimum standard of living. Various techniques can be applied in calculating this amount and once again any component flowing from asset ownership should be included, e.g. by using actual housing expenditures.

3) Total income. Thisuses an input measure approach, and has to makeinferences about the actual standard of living achieved. Due to asset accumulation, savings and borrowings, an income approach may differ from one based on expenditure. Surveys have shown a considerable mismatch in household rankings between thetwo series. O $\mathrm{n}$ balance, family income appears to be a more robust measure at the unit record level than family expenditure.

\section{Technical issues in poverty measurement}

As in most areas of social policy, there is a host of technical issues that require resolution beforemeasuring the extent of poverty. There is no correct answer: a pragmatic response will depend largely upon data availability and the policy question being confronted. Some of the issues are;

1) The appropriate unit of analysis - should it be the individual, the (extended) family, or thehousehold?
Clearly, the more inclusivethe definition, the lower the poverty estimate as more people with a low personal income will be aggregated with those on a higher income. For example, adult children (over 18 years) living at home should not be treated as a separate household, despite their individual eligibility for social security ben efits, without some adjustment covering the degree of resource sharing. (Sharing of resources within the whanau or aiga unit is however probably too difficult to adjust for.)

2) The time period over which the standard of living is measured. Fluctuationsin expenditure, dueto their lumpy nature, make that approach problematic, and many families show variations in income. The fortnightly measurement used in the Household Economic Survey (H ES) is too short, but the annual measure is too long, as poor families do not have sufficient savings or ability to borrow.

3) The appropriate equivalence scale to reflect adjustments for family size and composition. Subjective approaches tend to give a lower weighting for additional people, especially children, than those based on observed data, and thus finish up with more singles and couples, and less children, in poverty.

4) M easuring the extent of poverty. Information is required not just on the number or proportion of the population who fall below the poverty standard but also on the duration of their poverty, as well as the extent to which they fall below the poverty standard.

5) Adjusting the poverty measure through time. Irrespective of the standard of living adopted (as representing adequacy) in the initial establishment of a poverty threshold, every hardship measure has to be adjusted through time to take account general economic and social change. For income and expenditure approaches, the threshold can be adjusted in line with some measure of movements in average standards of living. Inevitably, policy changes (such as the implementation of user charges) can alter the minimum income required to achieve a given standard of living. So poverty standards have to be related to contemporary policy parameters as well as economic conditions. 


\section{Poverty measurement}

$\mathrm{N}$ ew Zealand has three innovative techniques for the measurement of poverty: living standards, as pioneered by the $M$ inistry of Social $D$ evelopment; income poverty thresholds, developed initially by Brian Easton and subsequently by the Poverty M easurement Project; and area-based deprivation scales, using Census data and developed by Peter Crampton.

\section{Living Standards}

Theliving standards approach is based on a questionnaire, and documents ownership and social participation restrictions, economising behaviour, financial and accommodation problems. It also includes a scale for self-assessment. The approach covers activities that families are forced to restrict, and then aggregates the restrictions into a master score to reflect living standards. M ost of the restrictions show that individuals have an ability to prioritise that reflects societal values - more people do without a dish-washer than good shoes, and prescriptions are more important than holidays.

There are weaknesses. For example, there is no measurement of social amenities such as access to parks, libraries, transport or shops. By providing each restriction with similar weight in the overall measure, the sense that one factor is different in quality from another is lost. This technique does however have one strong point. This stems from the ability to provide a useful description of what it is like to be poor - what one has to go without.

What then is the value of this approach for policy development and formulation? Here the answer does not seem to be clear-cut. The results are in broad agreement with what we learn from measurement of income poverty results. Thus, soleparent familiesemerge worse off on averagethan two parent families, and home ownership improves outcomes for the elderly in general. Low home ownership rates and the relative lack of assets accentuate the problems facing elderly $M$ aori.

\section{Income poverty thresholds}

The Poverty M easurement Project used a poverty threshold defined by focus groups, together with the results of the H ousehold Economic Survey. T he results lent statistical support to the flurry of small-scale, community-based studies emerging from the aftermath of the 1991 benefit cuts. (Those studies had indicated a significant degree of hardship for beneficiaries and statehousing tenants. In hindsight, it can be recognised that they provided an excellent insight into the impact of policy on vulnerable groups.)

The initial results of the PM P also provoked a political denial that poverty existed - together with claims that if it did exist this would be a short-term transition and/or was due to a lack of household budgeting skills. Soon however the medics and teachers were to enter the fray with evidence of poverty-related diseases and declining educational attainments due to lack of food and overcrowding. At that point, policy was directed to overcome the source of low income through the mandating of work (rather than directly raising benefit levels or child assistance).

If poverty is to be dealt with in a cost-effective manner income clearly has to be targeted as the key variable. A high poverty incidence is a combination of low market income and low efficiency of the tax/transfer system in reducing that poverty. Therearetwo policy variables - market income and the level of net transfers (tax rates and cash assistance). The appropriate mix of these is going to depend upon age, household type, potential for obtaining employment at an adequate wage, and other individual factors.

\section{A rea-based deprivation scales}

Individuals and households live in communities and, to some extent, outcomes will be influenced by group characteristics. Area-based deprivation scales will reflect, at the level of a Census mesh-block, material and social deprivations in a community. The variables (based on proportionsin an area) include: low equivalent income; with an income-tested benefit; no access to a car; adverse household occupancy; renting; educational qualifications and sole parenting. Thus some measure of asset ownership is collected, but unfortunately there is no measure of social capital. The resulting maps of deprivation are predictable - Taita has a higher index score than $\mathrm{K}$ handallah, and $\mathrm{O}$ tara is higher than Remuera - but the scale also shows that there are anomalous pockets of relative wealth (or poverty) in poor (or rich) suburbs respectively.

The approach is valuable for policy development on several counts: first, one can correlate the deprivation 
index with other social and economic outcomes, such as health status or educational attainment; secondly, the approach can be used for targeting social services delivery to offset degrees of deprivation; and thirdly, the approach provides valuable statistical information to community groups. This will assist their members in both advocacy and service delivery roles.

\section{Understanding poverty dynamics}

A gap in the Poverty M easurement Project is the measurement of how long people have been living in poverty. This can be tackled in two ways: first, one can look at the transfer of poverty from one generation to the next. Secondly, and possibly in combination with the first approach, one can assess the length of time that any household has been in poverty (and whether the experienceislikely to recur). The data at present available in N ew Zealand is inadequate for either task. We must therefore rely on indicative results, together with causal studies on intergenerational mobility, based on US data.

It is important to understand the causes of movement in or out of poverty, because the policy solutions may be quite different. To overcome benefit dependency, mandatory work-for-the-dole schemes and strict entitlement rules areneeded. Thepoverty model requires extra financial resources in the short term, with education/skill formation to improve earning capacity in thelong run. N eighbourhood models requiredispersal of housing as well as targeted social service delivery.

The incidence of poverty is not spread evenly across all households. Using U S data over a 15-year period, about two-thirds of children never experience poverty, and about ten percent have one spell of a year of inadequate income, but over the total period have more than adequate resources. 0 thers move in and out of poverty, with greater or lesser degrees of persistence, and there is a small group who are permanently poor. Roughly similar results come from analysis of those on social security benefits in $\mathrm{New}$ Zealand, with a significant proportion having just short spell of unemployment, whereas others are in receipt of benefits for a long period or are in and out of employment.

For the short-term poverty/unemployment group, adequacy of social security benefits is required as a shortterm alleviate. But the persistent and recurrent groupings require long-term solutions as well, through addressing the cause of the poverty problem such as a lack of education, labour market skills, location or ill-health.

\section{Poverty dynamics}

The comparative study undertaken by PM P does not indicate how long people have been poor for, and thus may not be a complete indicator of the effects of poverty or hardship. There are two types of poverty dynamic analysis, both requiring longitudinal data. First there is the inter-generational transference of poverty and low income: the extent to which children who grow up in a low income household al so becomelow-income households when adults. Second, there is the length of time that any household isin poverty, and whether that experience is one-off or subject to repetition. U nfortunately the longitudinal data in $\mathrm{N}$ ew Zealand are not really adequate for either of these two tasks, though some indicative results have been obtained.

The early data on intergenerational mobility, based on U S data, showed that individuals made their own fortune, rather than being dependent upon their family background. Subsequently, more careful analysis of much richer data-sets indicates far less mobility. The causal mechanisms of this mobility have also been investigated. The debates occur between those claiming the cause is one of benefit dependency (children growing up in homes where benefit use is high and long have lower aspirations, limited pressure to obtain secure and well-paid employment and feel less stigma about receiving a benefit), those claiming that the transference mechanism is one of poverty (children growing up in poor households have less resources and nutrition, poorer health, over-crowded housing and lower educational attainment and thus face the same labour market disadvantage as their parents) and those claiming that the neighbourhood that one grows up in results in type-casting in the labour market.

The policy solutions are quite different. To overcome benefit dependency, mandatory work-for-the-dole schemes and strict enforcement of entitlement rules are required. The poverty model requires extra financial resources in the short-term, with improvements in education and skills to increase employability and adequacy of wage rates in the long-term. N eighbourhood models, as measured by deprivation scales below, require housing dispersal policies as well as targeted social service delivery. 


\section{Conclusions}

M easuring poverty or hardship is fraught with a host of technical issues and value judgements. There is no single correct measure of poverty, and no simple dividing line between the poor and the non-poor. The afflictions of poverty are not avoided if one is marginally above a particular poverty standard, especially if one has been on a low standard of living for some period of time.

Both sides of the boundary line are foggy. Those who are marginally below the poverty standard may not experience adverse outcomes if they have adequate assets and some capacity for self-sufficiency. This is particularly true if the fall in income is only for a short period. The fact that there is no consistency across different techniques for measuring poverty offers a range of perspectives on such issues. Each perspective can thus complement others in the process of determining policy.

The income measure of poverty is more useful for policymakers, since it relates directly to the instrument that the government can control, namely cash support. Annual, cross-sectional data on the incidence and severity of poverty and on the effectiveness of existing instruments provide valuable supplementary information. It can be readily used by any government interested in mitigating poverty or in monitoring the impact of previousadjustments to policy on the poorest members of society.

The real picture of poverty cannot be formed on the basis of cross-sectional results: this requires longitudinal studies, and there are as yet no robust $\mathrm{N}$ ew Zealand examples. Theliving standards approach does provide an excellent description of poverty, and fits neatly with the public perception of inadequate outcomes. It provides a realistic check on the results of the income-based method, and offers guidance on the adequacy of benefit levels. This can also help in targetting resources to those groups in greatest need: for example, home-owning elderly are less in need of additional assistance than families with children The same information can also inform the in-kind versus cash debate. Unless living standard estimates are widened to incorporate the degree of social capital within a community, the results may however be less helpful for policy purposes.
In short, if a government is concerned about the alleviation of poverty, it will require some poverty standard to be established in order to direct resources to the area of greatest return. M easurement is the first step in this process, and this requires a threefold combination of:

- cross-sectional income measures

- verified by living standard outcomes

- and supported by longitudinal studies for information on both the persistence of poverty and its ultimate causes.

Associate Professor Robert Stephens teaches in the School of Government, Victoria University of Wellington and has collaborated in preparing this paper with $\mathrm{C}$ harles Waldegrave, a co-founding member of the Poverty M easurement Project. 